\title{
Cytogenetic differences in breast cancer samples between German and Japanese patients
}

\author{
J Packeisen, K Nakachi, W Boecker, B Brandt, H Buerger
}

J Clin Pathol 2005;58:1101-1103. doi: 10.1136/icp.2004.022392

Background: Japanese and German breast cancer cases differ substantially in the frequency of egfr amplification. Aims: To unravel further the cytogenetic differences between Japanese and German breast cancer cases.

Methods: Forty one Japanese breast cancer cases were evaluated by means of comparative genomic hybridisation $(\mathrm{CGH})$. The results were compared with the $\mathrm{CGH}$ results from 161 German breast cancer cases.

Results: The mean number of genetic alterations/case was significantly higher in German premenopausal patients with breast cancer than in their Japanese counterparts. Japanese breast cancer cases revealed a higher number of chromosome $17 p$ losses. Losses of $8 p$ were associated with oestrogen receptor (ER) negativity in Japanese patients with breast cancer, whereas in the German patients gains of $3 q$ and $6 q$ were associated with the lack of ER expression.

Conclusions: The interethnic differences of invasive breast cancer are reflected by cytogenetic aberrations, which are also associated with the differential expression of the ER.

S ubstantial epidemiological and clinical differences have been reported between Japanese and white patients with breast cancer. ${ }^{1}$ Most cytogenetic studies published so far, using comparative genomic hybridisation (CGH) as a screening technique for the detection of unbalanced cytogenetic alterations within a given tumour, have concentrated on white women. ${ }^{2-4}$ In contrast, little is known about the cytogenetic aberrations in breast cancer in patients of Asian origin. ${ }^{5}$

Significant differences are known to exist between white and Asian populations for many polymorphic DNA sequences. A study published by our group previously identified a polymorphic sequence in intron 1 of the epidermal growth factor receptor (EGFR) gene (egfr) that had a significantly longer CA repeat stretch in Japanese than in German women. In vitro and in vivo experiments showed that the longer CA repeat stretch in Japanese patients was associated with a higher frequency of egfr gene amplification ${ }^{6}$ and EGFR expression. Therefore, it is possible that other polymorphic sites exist that have distinct chromosomal aberrations in the different ethnic subgroups.

"Significant differences are known to exist between white and Asian populations for many polymorphic DNA sequences"

\section{MATERIAL AND METHODS}

Forty one cases of Japanese breast cancer were analysed by $\mathrm{CGH}$ and these results were compared with those from 161 invasive breast tumours from German women, originating from the files of the Gerhard-Domagk Institute of Pathology. None of the patients had preoperative treatment. Table 1 provides further details of the investigated tumour samples. The Japanese breast cancer cases originated from the files of the Saitama Cancer Centre Hospital, Japan. The method of CGH analysis, the criteria for the evaluation of genetic alterations, and the immunohistochemical evaluation of the steroid receptor content were performed as described previously. ${ }^{7}$

\section{Statistical tests}

Statistics were performed using Fisher's exact test and the Mann-Whitney $U$ test. p Values were two tailed and not adjusted for multiple comparisons; $p$ values $<0.05$ were considered significant.

\section{RESULTS}

In accordance with the literature, 28 of $41(68 \%)$ of the Japanese and 51 of 161 (32\%) of the German patients with breast cancer were premenopausal. The mean age was 51.9 (SD, 13.1) and 59.9 (SD, 15.0) years in Japanese and German patients with breast cancer, respectively $(p<0.01)$. Table 1 provides a detailed characterisation of the patients. Table 2 provides an overview of the most common quantitative cytogenetic aberrations.

A detailed characterisation of the German patients with breast cancer has been published previously. ${ }^{7-9}$ On average, the German breast cancer cases revealed 8.5 alterations/case (9.6 and 8.1 in premenopausal and postmenopausal patients, respectively), whereas the Japanese patients with breast cancer had a significantly lower average number of alterations/case $(7.2 ; 6.3$ and 8.7 in premenopausal and postmenopausal patients, respectively; $\mathrm{p}<0.05)$. ER positive cases had a lower average number of alterations/case compared with ER negative tumours in both subgroups (7.5 $v 10.5(\mathrm{p}<0.01)$ in German and $6.2 v 8.7(\mathrm{p}=0.11)$ in Japanese patients with breast cancer). ER negative tumours showed a similar frequency of aberrations irrespective of menopausal status in German patients, whereas postmenopausal Japanese patients with ER negative tumours showed a clear increase in cytogenetic alterations. The Japanese ER positive subgroup showed a higher rate of $16 \mathrm{q}$ losses, whereas ER negative cases showed an increased rate of $8 \mathrm{p}$ losses $(\mathrm{p}<0.05$ for both parameters). German ER positive tumours also had a significantly increased rate of 16q losses $(p<0.05)$ and a decreased rate of $3 q(p<0.01)$ and $6 q$ gains $(\mathrm{p}<0.05)$.

The recurrent changes seen most frequently in German and Japanese breast cancer cases were gains of 1q, 3q, 6q, 8q, 17q, and 20q in addition to losses of 6q, 8p, 11q, 13q, and 16q. 17p losses were predominantly seen in Japanese patients with breast cancer $(\mathrm{p}<0.001)$.

Abbreviations: $\mathrm{CGH}$, comparative genomic hybridisation; EGFR, epidermal growth factor receptor; ER, oestrogen receptor 


\begin{tabular}{|c|c|c|}
\hline & Japanese & German \\
\hline Characteristic & $n=41$ & $n=161$ \\
\hline \multicolumn{3}{|l|}{ Menopausal status } \\
\hline Premenopausal & $28(68 \%)$ & $51(32 \%)$ \\
\hline Postmenopausal & $13(32 \%)$ & $110(68 \%)$ \\
\hline \multicolumn{3}{|l|}{ Stage } \\
\hline 1 & $14(35 \%)$ & $51(32 \%)$ \\
\hline$\| \mathrm{a}$ & $11(27 \%)$ & $40(25 \%)$ \\
\hline$\| \mathrm{lb}$ & $5(11 \%)$ & $24(15 \%)$ \\
\hline Illa & $4(10 \%)$ & $18(11 \%)$ \\
\hline $\mathrm{lllb}$ & $4(10 \%)$ & $20(12 \%)$ \\
\hline IV & $3(7 \%)$ & $8(5 \%)$ \\
\hline \multicolumn{3}{|l|}{ Grade } \\
\hline 1 & $8(19 \%)$ & $18(11 \%)$ \\
\hline ॥I & $18(44 \%)$ & 77 (48\%) \\
\hline III & $15(37 \%)$ & $66(41 \%)$ \\
\hline \multicolumn{3}{|l|}{ Tumour type } \\
\hline Ductal invasive & $36(87 \%)$ & $121(75 \%)$ \\
\hline Lobular invasive & $5(13 \%)$ & $25(16 \%)$ \\
\hline Miscellaneous subtypes & & $15(9 \%)$ \\
\hline \multicolumn{3}{|l|}{ Oestrogen receptor status } \\
\hline Negative & $18(43 \%)$ & $65(40 \%)$ \\
\hline Positive & $23(57 \%)$ & $96(60 \%)$ \\
\hline
\end{tabular}

The rate and distribution of high level gains, indicative of gene amplification, was similar in both ethnic subgroups (36\% in German patients compared with $44 \%$ in the Japanese ones).

Other than the above described correlations between cytogenetic alterations and clinicopathological parameters, no distinct cytogenetic alterations were found in Japanese patients with breast cancer.

\section{DISCUSSION}

Recently, significant differences have been shown in relation to the length of a polymorphic sequence within the intron 1 of egfr, the frequency of egfr mutations, and the expression of EGFR between Japanese and German patients with breast cancer. ${ }^{6}$ Interestingly, similar differences have also been described for activating mutations of egfr in Japanese and white patients with lung cancer. ${ }^{10}$

The idea of different genotypes leading to a similar phenotype led us to the comparative cytogenetic analysis of Japanese and German patients with breast cancer. In addition to the differences in egfr amplification previously described in this series, a significantly higher incidence of $17 p$ losses was found in Japanese breast cancer cases compared with German breast cancer cases. The frequency of $17 p$ losses was even higher than that seen in German ductal invasive G3 carcinomas, which generally display the highest frequency of $17 p$ losses. ${ }^{3}{ }^{11}$ This feature was not affected by menopausal or ER status, and these results are still open to interpretation. The role of p53 (with its chromosomal locus at 17p13.1) in this scenario remains unclear, because p53 mutations are associated with worse prognosis and a lower degree of histopathological differentiation, features less common in Japanese breast cancer. ${ }^{12}$ Alternatively, another putative tumour suppressor gene within $17 \mathrm{pl} 3$ might contribute to breast carcinogenesis predominantly in Japanese patients with breast cancer $^{13}{ }^{14}$; however, alterations within this suspected tumour suppressor gene appear to be associated with highly proliferative breast cancers with a poor prognosis, ${ }^{15}$ which again is contradictory to the tumour biological features seen in Japanese patients with breast cancer in general and also in our series.

A higher average number of cytogenetic alterations/case correlates with an increased recurrence rate in node negative
Table 2 Summary of cytogenetic alterations in the Japanese and German breast cancer subgroups

\begin{tabular}{|c|c|c|c|}
\hline & Germany & Japan & p Value \\
\hline \multicolumn{4}{|c|}{ Mean number of cytogenetic alterations/case } \\
\hline All & 8.5 & 7.2 & \\
\hline Premenopausal & 9.6 & 6.3 & $\mathrm{p}<0.05$ \\
\hline Postmenopausal & 8.1 & 8.7 & \\
\hline ER+ & 7.5 & 6.2 & \\
\hline \multirow[t]{2}{*}{ ER- } & 10.5 & 8.7 & \\
\hline & $p<0.01$ & $p=0.11$ & \\
\hline \multicolumn{4}{|c|}{ Frequency of the most recurrent cytogenetic alterations } \\
\hline lq gains & $70 \%$ & $78 \%$ & NS \\
\hline $3 q$ gains & $23 \%$ & $11 \%$ & NS \\
\hline $6 q$ gains & $11 \%$ & $14 \%$ & NS \\
\hline $8 q$ gains & $49 \%$ & $46 \%$ & NS \\
\hline $17 q$ gains & $18 \%$ & $26 \%$ & NS \\
\hline $20 q$ gains & $20 \%$ & $17 \%$ & NS \\
\hline $6 q$ losses & $21 \%$ & $19 \%$ & NS \\
\hline $8 p$ losses & $34 \%$ & $26 \%$ & NS \\
\hline $13 q$ losses & $26 \%$ & $19 \%$ & NS \\
\hline $16 q$ losses & $53 \%$ & $39 \%$ & NS \\
\hline $17 p$ losses & $22 \%$ & $63 \%$ & $\mathrm{p}<0.001$ \\
\hline \multicolumn{4}{|c|}{ Frequency of the most common chromosomal high level gains } \\
\hline $8 q$ & $18 \%$ & $21 \%$ & NS \\
\hline $11 q$ & $10 \%$ & $7 \%$ & NS \\
\hline $17 q$ & $18 \%$ & $12 \%$ & NS \\
\hline $20 \mathrm{~g}$ & $6 \%$ & $5 \%$ & NS \\
\hline
\end{tabular}

breast cancer, and therefore with overall prognosis. ${ }^{16}$ In accordance with this, there was a slightly increased average number of genetic alterations in all German breast cancer cases and a decreased number of genetic alterations in German postmenopausal breast cancer cases. Interestingly, there was a significantly higher average number of genetic alterations/case in the German premenopausal patients with breast cancer than in their Japanese counterparts.

"It is interesting that, irrespective of menopausal status, our German patients with oestrogen receptor (ER) negative cancer had a significantly higher average number of cytogenetic alterations/case compared with ER positive patients"

The regulation of ER expression between Japanese and German patients with breast cancer is similar in some respects but different in others. Different levels of ER expression in benign breast tissue between Japanese and white populations have been reported as an underlying cause of differences in breast cancer incidence between these two populations. The exact reasons for this observation are unclear, although the influence of food habits has been discussed. ${ }^{17}$ A higher rate of ER negativity has been found in Japanese postmenopausal patients with breast cancer compared with matched white patients, and this correlated with a worse prognosis in the Japanese patients. ${ }^{18}$ It is interesting that, irrespective of menopausal status, our German patients with ER negative cancer had a significantly higher average number of cytogenetic alterations/patient $(\mathrm{p}<0.01)$ compared with ER positive patients. This was also true for our Japanese patients with breast cancer, with the exception of premenopausal patients, in whom no quantitative cytogenetic impact of ER expression could be measured.

However, similar cytogenetic alterations associated with the regulation of ER expression appear to be present in German and Japanese patients with breast cancer. This is especially true for chromosomal $16 \mathrm{q}$ losses in ER positive carcinomas in both ethnic groups, as described previously. ${ }^{11} 19$ Our series did not reveal the biological importance of $8 \mathrm{p}$ 


\section{Take home messages}

- The average number of genetic alterations/case was significantly higher in German premenopausal patients with breast cancer than in their Japanese counterparts

- There were a higher number of chromosome $17 p$ losses in Japanese patients

- Losses of $8 p$ were associated with oestrogen receptor (ER) negativity in Japanese patients with breast cancer, whereas in the German patients gains of $3 q$ and $6 q$ were associated with the lack of ER expression

- Thus, the interethnic differences of invasive breast cancer are reflected by cytogenetic aberrations, which are also associated with differential expression of ER

losses associated with ER negativity in the German breast cancer cases. Losses at this site were found in all but one CGH study on white patients with breast cancer. ${ }^{19}{ }^{20}$ The number of Japanese tumours investigated in our series might be too small to draw definite conclusions concerning $3 \mathrm{q}$ and $6 \mathrm{q}$ gains in Japanese patients with breast cancer because these changes are relatively rare events in breast cancer. Gains of $3 q$ and $6 q$ have been shown to be associated with an increased level of telomerase activity, cytogenetic instability, and tumour proliferation, suggesting an interplay between these parameters. ${ }^{21}$

In summary, our results show that there are cytogenetic differences between Japanese and German breast cancer cases. Further studies are needed to define the extent to which these differences are causative or merely a reflection of other underlying genetic disturbances that are not detectable by means of CGH.

\section{Authors' affiliations}

J Packeisen, Institute of Pathology, 49076 Osnabrück, Germany K Nakachi, Department of Epidemiology, Saitama Cancer Centre, Saitama 362-0806 Japan

W Boecker, H Buerger, Institute of Pathology, University of Muenster, 48149 Muenster, Germany

B Brandt, Institute of Clinical Chemistry and Laboratory Medicine, University of Muenster

Correspondence to: Professor H Buerger, Institute of Pathology, Westfälische Wilhelmsuniversität Münster, Domagkstr. 173, 48149 Münster, Germany; burgerh@uni-muenster.de

Accepted for publication 18 February 2005

\section{REFERENCES}

1 Sakamoto G, Sugano H. Pathology of breast cancer: present and prospect in Japan. Breast Cancer Res Treat 1991;18(suppl 1):S81-3.

2 Ried T, Just $\mathrm{KE}$, Holtgreve Grez H, et al. Comparative genomic hybridization of formalin-fixed, paraffin-embedded breast tumours reveals different patterns of chromosomal gains and losses in fibroadenomas and diploid and aneuploid carcinomas. Cancer Res 1995;55:5415-23.

3 Buerger H, Otterbach F, Simon R, et al. Different genetic pathways in the evolution of invasive breast cancer are associated with distinct morphological subtypes. J Pathol 1999; 189:521-6.

4 Roylance R, Gorman P, Harris W, et al. Comparative genomic hybridization of breast tumours stratified by histological grade reveals new insights into the biological progression of breast cancer. Cancer Res 1999;59:1433-6.

5 Fung LF, Wong N, Tang N, et al. Genetic imbalances in pT2 breast cancers of southern Chinese women. Cancer Genet Cytogenet 2001;124:56-61.

6 Buerger H, Packeisen J, Boecker A, et al. Allelic length of a CA dinucleotide repeat in the egfr gene correlates with the frequency of amplifications of this sequence-first results of an inter-ethnic breast cancer study. J Pathol 2004;203:545-50.

7 Buerger H, Mommers E, Littmann R, et al. Ductal invasive G2 and G3 carcinomas of the breast are the end stages of at least two different lines of genetic evolution. J Pathol 2001;194:165-70.

8 Agelopoulos K, Tidow N, Korsching E, et al. Molecular cytogenetic investigations of synchronous bilateral breast cancer. J Clin Pathol 2003;56:660-5.

9 Buerger H, Simon R, Schaefer KL, et al. Genetic relationship of lobular carcinoma in situ, ductal carcinoma in situ and associated invasive carcinoma of the breast. Mol Pathol 2000;53:118-21.

10 Paez JG, Janne PA, Lee JC, et al. EGFR mutations in lung cancer: correlation with clinical response to gefitinib therapy. Science 2004;304: 1497-500.

11 Tirkkonen M, Tanner M, Karhu R, et al. Molecular cytogenetics of primary breast cancer by CGH. Genes Chromosomes Cancer 1998;21:177-84.

12 Higuchi CM, Serxner SA, Nomura AM, et al. Histopathological predictors of breast cancer death among Caucasians and Japanese in Hawaii. Cancer Epidemiol Biomarkers Prev 1993;2:201-5.

13 Coles C, Thompson AM, Elder PA, et al. Evidence implicating at least two genes on chromosome 17p in breast carcinogenesis. Lancet 1990;336:761-3

14 Cornelis RS, van Vliet M, Vos CB, et al. Evidence for a gene on 17p13.3, distal to TP53, as a target for allele loss in breast tumors without p53 mutations. Cancer Res 1994;54:4200-6.

15 Merlo GR, Venesio T, Bernardi A, et al. Loss of heterozygosity on chromosome 17 p13 in breast carcinomas identifies tumors with high proliferation index. Am J Pathol 1992;140:215-23.

16 Isola JJ, Kallioniemi OP, Chu LW, et al. Genetic aberrations detected by comparative genomic hybridization predict outcome in node-negative breast cancer. Am J Pathol 1995;147:905-11.

17 Lawson JS, Field AS, Champion S, et al. Low oestrogen receptor alpha expression in normal breast tissue underlies low breast cancer incidence in Japan [letter]. Lancet 1999;354:1787-8.

18 Stemmermann GN. The pathology of breast cancer in Japanese women compared to other ethnic groups: a review. Breast Cancer Res Treat 1991; 18(suppl 1):S67-72.

19 Richard F, Pacyna Gengelbach M, Schl Fleige B, et al. Patterns of chromosomal imbalances in invasive breast cancer. Int J Cancer 2000;89:305-10.

20 Rennstam K, Ahlstedt-Soini M, Baldetorp B, et al. Patterns of chromosomal imbalances defines subgroups of breast cancer with distinct clinical features and prognosis. A study of 305 tumors by comparative genomic hybridization. Cancer Res 2003:63:8861-8.

21 Loveday RL, Greenman J, Drew PJ, et al. Genetic changes associated with telomerase activity in breast cancer. Int J Cancer 1999;84:516-20. 